THE JOURNAL OF PHILOSOPHICAL ECONOMICS:

REFLECTIONS ON ECONOMIC AND SOCIAL ISSUES

Volume XIV Issues 1-2

Spring-Autumn 2021

ISSN: $1843-2298$

EISSN: $1844-8208$

Publication date:

20 November 2021

Paper format: $16.5 \times 23.5 \mathrm{~cm}$

Copyright note:

Authors retain unrestricted copyright and all publishing rights in compliance with the Creative Commons license CC BY-NC-SA.
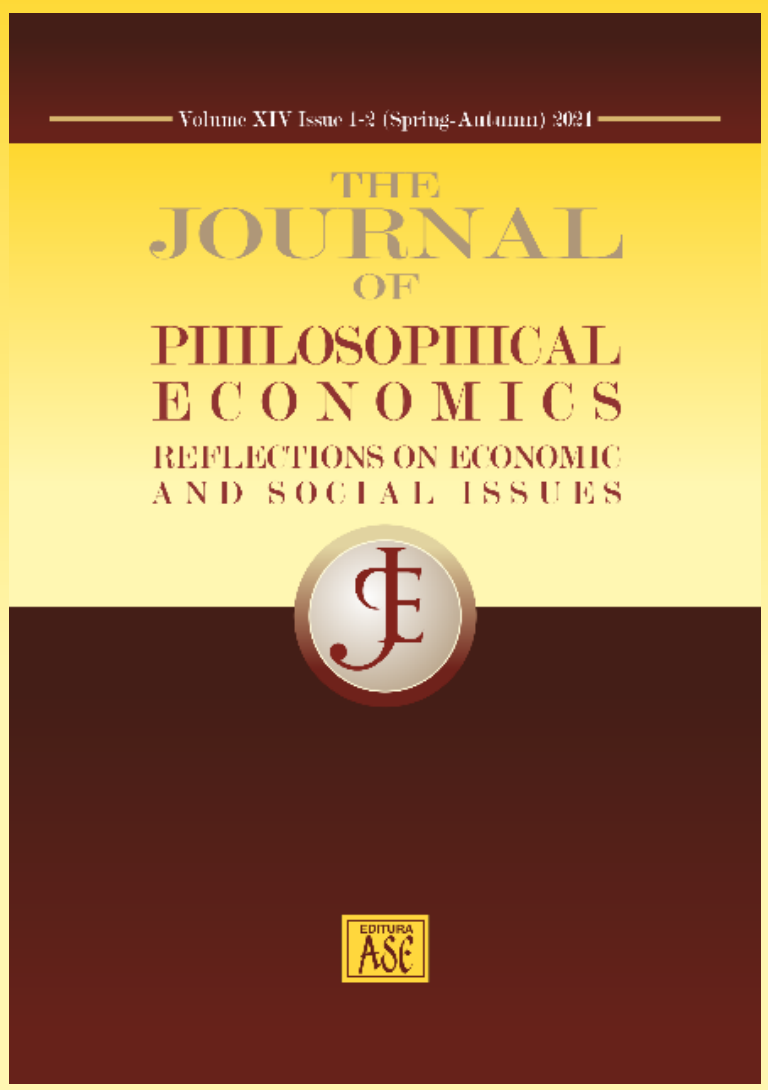

\title{
'Everything You Know is Wrong'. A series of challenges and responses
}

Frederic B. Jennings Jr. 


\title{
'Everything You Know is Wrong'. A series of challenges and responses
}

\author{
Frederic B. Jennings Jr.
}

In 1974, the Firesign Theater issued a comedy album entitled 'Everything You Know Is Wrong.' It was funny. This is not. Nearly all I was taught about economics needs revision. How could this be? We live in a Firesign Theater nightmare. Let me count the ways, though in many ways they are countless. I'll start with just a few points.

Wrong \#1 about scarcity: Economics is said to be all about scarcity, tradeoffs and choice. The whole notion of 'opportunity cost' as the value of foregone options says economics is about choice. That has been how we were all taught to think about things in this realm.

Answer to Wrong \#1 about scarcity: I used to believe in this scarcity view, back when I bought what was taught. But we all live in a world of connected causalities and network complexities, where nothing is simple or partial save in our own blind treatments thereof. A network contains two types of relation, and not just one, as so often claimed. If substitutes are bundled together with complements in a composite tangle, which is ever the case in networks, 'industries' as composition rules spread incorrect 'truths.' Economics is not just about substitution, tradeoffs, and scarcity; that's too narrow a view. We must include complementary interdependencies, which open a Pandora's Box of even more challenging questions. Economics is not just scarcity; it also embraces abundance among complementary goods.

Wrong \#2 about the efficiency of competition: These two concepts are treated as synonymous in economics. Competition is posed as a standard of efficiency. If a market is competitive, then it is seen as efficient, and vice versa. For any system to be efficient, it must be competitive, which validates its efficiency. This connection is seldom questioned, much less contravened.

Received: 9 August 2021 
Jennings Jr. B. Frederic (2021), Everything You Know is Wrong'. A series of challenges and responses, The Journal of Philosophical Economics: Reflections on Economic and Social Issues,

Answer to Wrong \#2 about the efficiency of competition: Substitution calls for competition, this is so. But complementarity inverts this story into a case for cooperation. Networks subsume both relations in a nondecomposable mix, which leaves us with no general answer about the best institutional structure. So are we left with no institutional guidance on this point? The case for competition is specific to substitutional links; it should be balanced against a strong case for cooperation among complements. This suggests we need to consider which of these two forms of interdependence is dominant in a specific context, and not just assume substitution everywhere. Every case - or any transaction - entails spreading effects spawning complementary or positive feedbacks in combination with substitutional or negative feedbacks. Both are always in play. In the presence of complementarity, efficiency shifts to cooperation and competition fails.

Wrong \#3 about equilibrium models: Models of equilibrium based on substitution assumptions (that depend on a claim of diminishing returns or rising unit costs of production, so models lead to stable outcomes that truly exist) are required for scientific closure. Negative feedbacks shall balance economic concerns sufficiently to allow equilibria, as well as to forestall 'wreckage'(cf. Hicks 1939, pp. 83-85).

Answer to Wrong \#3 about equilibrium models: The problem is that there are no equilibria out in the world. Myrdal - a Nobel Laureate - denied any such claim (cf. Myrdal 1978, pp. 772-74). If our realms are always in flux, perhaps we should accept this reality in how we frame it. Knowing we have no equilibria on which we can rely might spur us onto a novel landscape of insights still undiscovered before us, like Boulding's and Newton's 'ocean of truth' (cf. Boulding 1966, pp. 33-36). We should face such questions and deal with doubt, to learn whether 'Everything We Know Is Wrong'! Incorrect answers should not be shunned; they bring great opportunities for new learning by eager intellects. Questioning what we think can be encouraged and not denied. That is how we advance understanding.

Wrong \#4 about diminishing returns: No lesser luminaries than Frank Knight and Armen Alchian declared diminishing returns a 'general law' long deemed 'universally valid'(cf. Knight 1924, pp. 136-37 and Alchian 1968, pp. 319-20). So within their referential frame, substitution applies everywhere with increasing 
Jennings Jr. B. Frederic (2021), Everything You Know is Wrong'. A series of challenges and responses, The Journal of Philosophical Economics: Reflections on Economic and Social Issues, XIV (1-2), 208-217

returns an exception. Standard doctrines are used for most purposes and anomalies shoved aside. Here rising costs are the rule, from which such departures lack credible substance.

Answer to Wrong \#4 about diminishing returns: The case for diminishing returns pertains just to short-run phenomena where resources are fixed or slow to adjust. Generalized increasing returns (or falling long-run costs) were endorsed by Pigou in the late 1920s and Kaldor almost 50 years later (cf. Pigou 1927, 1928 and Kaldor 1972, 1973, 1975). Even Hicks retracted his 'getaway,' even if far too late in the game to avoid the damage it did (cf. Hicks 1939, pp. 83-85; 1977, pp. v-vii and Jennings 2015). The economic case for increasing returns in all long-term production is incontrovertible, logically, and empirically (cf. Jennings 2015, 2016a). In 1939, Hicks said this would lead to 'wreckage' (cf. Hicks 1939, pp. 8385). Kaldor related increasing returns to generalized complementarity, yielding a claim for cooperation as efficient (though he did not add that truth). Complementarity, if universal, means equilibrium models stay open, obviating existence proofs. An economy is an ecology, always in motion, never at rest. Here we need dynamic complex systems; orthodox standards be damned! Diminishing returns cannot be upheld except for an instant term. Mainstream models based on this claim are stuck in short-term modes, at the cost of a larger view.

Wrong \#5 about rationality: We all make choices with vision clear regarding our wants and priorities. This is a pathway, if thought through. Rationality yields behavioral inferences from visible facts without epistemological filters based on a sorting of falsity and truth out from belief. We can assume our cognitive faculties operate truly enough to warrant valid choice, such that economic consequences shall be objectively based on facts, not on subjective fantasy and desire.

Answer to Wrong \#5 about rationality: The whole case for 'rationality' in economics shall need revision, based on cognitive framing issues addressed by Kahneman, Tversky and others (e.g., Kahneman, Slovic and Tversky 1982; Kahneman and Tversky 2000). In networks, all we do ripples outward forever on everything else. If so, where are the analytical limits within which we frame meaning? (cf. Georgescu-Roegen 1970, pp. 2-3, discussed in Jennings 2016b, pp. 64-65). Our resolution may be horizonal, lying in the range of awareness secreted in expectation (e.g., Jennings 1985, 2008, 2010, 2012ab, 2017ab). But this shall 
Jennings Jr. B. Frederic (2021), Everything You Know is Wrong'. A series of challenges and responses, The Journal of Philosophical Economics: Reflections on Economic and Social Issues, XIV (1-2), 208-217

likely carry us well beyond the bounds of what we know, as Simon said! (cf. Simon 1982-97, passim.)

Wrong \#6 about our use of Marshallian scissors to mind our Ps and Qs: Supply and demand analyses reveal how pricing works. These are basic concepts and building blocks. Supply and demand cannot be abandoned while leaving anything for us to crunch. This is surely a solid foundation on which we can ground our understanding of economic pricing behavior.

Answer to Wrong \#6 about our use of Marshallian scissors to mind our Ps and Qs: We should focus on what we actually see emerging from real decisions. We set a price to fix a linear locus along which a flow of sales aligns with what we expect, as we tweak them both to meet. The rest of these curves pose foregone options that are unobserved; they but exist in the mind of an agent as 'opportunity cost.' Nothing else on these curves is real, save for one jiggling linear point determined by price and desire. The rest of the framework casts a fantastic conception devoid of realistic content. We think we know more than we do, within this specious frame.

Wrong \#7 about deductive validity: We either impose realistic conditions - or, if Friedman is right, abandon fact (Friedman 1953) - to fashion models with objective validity. This is how we advance an academic career, rending concepts in systems of thought. Nothing else matters, as long as economic colleagues applaud. This is the way we define success in our academic community.

Answer to Wrong \#7 about deductive validity: Let us not abstract away from the actual use of frameworks. Theory is not decoration nor flowers on a wall. How we think guides action; it directs all we do. Learning comes from induction, with no prescriptive answers. We cast about for 'regularities' (Samuelson 1963, pp. 235-36), often to no avail, lacking prior assurance or registered destinations. We grope for reasons, shoveling common features out of unique continua to resolve vital lessons stemming from broad and mysterious seeds of experience. There is no map pointing our way over these uncharted depths. There are no formulae here, only an open search for answers to questions we frame out of fabrics specific to our own (inherently personal) (cf. Polanyi 1958) experience and knowledge.

Wrong \#8 about 'given' wants and tradeoffs: We can treat intention as stably fixed to predict decisions based on defining guideposts to bliss in our values, 
Jennings Jr. B. Frederic (2021), Everything You Know is Wrong'. A series of challenges and responses, The Journal of Philosophical Economics: Reflections on Economic and Social Issues, XIV (1-2), 208-217

striving to a summit of happiness past less statuesque swellings. We are not so malleable in aim or belief, framing grounds for insights into social behavior. That may be enough for theory; it is surely all we need to proceed.

Answer to Wrong \#8 about 'given' wants and tradeoffs: Nothing in our social lives is stable or predictable, much less ever known. Desires sway to whims, so adapting to all response. Who ruled the context of action to be frozen in place? Everything moves in chaotic curls (cf., e.g., Emery and Trist 1965, pp. 243, 253); nothing is still or relaxed. There is no stand on this shifting ground upon which our theories subsume.

Wrong \#9 about theory: We can assume whatever we wish. Friedman deemed that $O K$, even necessary and perhaps unavoidable, so why not frame events as desired? Let us set free our creative fantasy and craft tales of how we might act with respect to the goals we adopt. Theory is sufficiently open to stories that we need not care. Really, one might deploy any means to analyze social behavior. Anything goes, in this situation! (Feyerabend 1975). So might we progress.

Answer to Wrong \#9 about theory: How we frame matters in all sorts of ways; it defines and determines all options and acts. Every choice asserts some value, rising from meaningful purpose in context. The worth of theories stems from their role as a guide to action in fancying outcomes among which we choose. Theory is not decoration! How we think colors all we do. Realistic constructs shape projection, conducting us surely through a bewildering complex of fact and delusion, helping us sort it all out. Theory counts at every step, portraying outcomes, shaping options and directing attention to their potential worth as best defined.

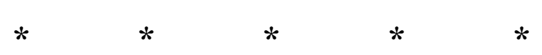

What has been said thus far? Economics is not just about scarcity as its subject; a network combines substitutes with complements in both their shortfalls and bounties. Competitive frames are not always efficient in every application; the question is one of fundamentality. We live inside unfolding continua where equilibrium models stay open, denying us any existence proof for scientific acceptance. The 'universal law' of diminishing returns can be tossed out too; all long-term analyses stand on declining cost, transgressing clear representation 
Jennings Jr. B. Frederic (2021), Everything You Know is Wrong'. A series of challenges and responses, The Journal of Philosophical Economics: Reflections on Economic and Social Issues, XIV (1-2), 208-217

by equilibrium models. A more realistic frame must therefore resort to a network conception.

As for rationality, we cannot see beyond our ranges of vision that touch uncertainly outward into a cognitively bounded domain (Jennings 2012ab). The Marshallian scissors are not what we thought, or taught to our ruly students; sales and prices shift incessantly and dance in accord with everything else. Also remember that deduction, devoid of valid depiction, turns us into inhuman nodules and away from each other. Realism matters! So will all our idolatrous screens subvert our resources and undermine dreams, if not our ruinous civilization.

So where does all this strand us? Out on a desert with nothing to say? Or are these grounds for a new release of vitality in economics? Let us suggest a few ways ahead that may open new doors. Are we ready for this?

We have no efficiency answer in networks: substitution wants separation while complementarity yields integration; here we find a tangle of both. Which is more important? Can we determine their relative weight in any specific context? Human connection, the nature of which cannot be abstracted from setting and purpose, is not so readily opened. We coexist in an ongoing balance of factors stolidly interdependent. That balance itself, however, responds to any 'horizon effect', namely, an ordinal shift of planning horizons in private or social space (since both adjust together). Here is a welfare goal: longer horizons are to be sought; we might organize systems for that, depicting cooperation as far more efficient than opposition (Jennings 2009, 2012ab).

Learning entails information acquired through complementary knowledge exchange, and that takes nothing away from its source. What we know will spread without cost. There is no scarcity here, among intangible goods. All are shared to maximum benefit: this is a case for integration where rivalry yields suffocation, both among goods and in personal growth.

These social and cultural processes - such as in education and ethics - along with all ecological systems are relentlessly complementary, in which competition must fail. Look at our results! Socially, as we dumb ourselves down in an openly myopic culture resistant to facing - much less solving - growing ethical and ecological loss, we wonder why our systems slip precipitously and dangerously 
Jennings Jr. B. Frederic (2021), Everything You Know is Wrong'. A series of challenges and responses, The Journal of Philosophical Economics: Reflections on Economic and Social Issues, XIV (1-2), 208-217

into this scary, yawning abyss. It's the economy, stupid! Or is it our institutional structures? We think competition will set us free, ignoring self-fashioned disasters.

All of this stems from economists' stubborn denial of falling cost during the postwar years starting in 1939 (cf. Hicks 1939, pp. 83-85; 1977, pp. vvii, as discussed in Jennings 2015). Samuelson, Arrow, Debreu, many others - most of them honored as Nobel Laureates - slavishly followed the 'Hicksian Getaway' (Jennings 2015) over an unrealistic cliff, forsaking common sense and truth as seen throughout the cost debates almost a century past. All of this slid economics into a fantasyland of foolishness, off from an institutional understanding of interdependence, systems theory and network complexity as economic conundra. We need to emerge from this Age of Denial into realistic construction, and deal with the world as it is, or at least in as truthful a form as we can, no longer riddled by all these Friedmaniac canons (e.g., cf. Friedman 1953, chapter 1, Reder 1982, 1987, and Boland 1980, 1986).

Our rational limits, Simon says, suggest a route to horizonal theory as a way out of the mess (Simon 1983, esp. p. 107; Jennings 2008). Social horizon effects show how rivalrous systems spawn a myopic culture in self-destruct mode that we cannot see outside a cognitive frame. Models unfit to applications - such as standard doctrines supposing substitution in long-term analyses - sabotage our understanding with no warning alert. This is our case for realism as a route to horizonal growth in the direction of economic advance; the rest of the way is a largely uncharted domain across an 'ocean of truth' that we must strive to make clear. A first step is to recognize that 'Everything You Know Is Wrong.' That might at least start discussion. The path ahead is wide open to us.

\section{References}

Alchian, Armen A. (1968), 'Cost', in the International Encyclopedia of the Social Sciences, Vol. 3, New York: Macmillan and Free Press, pp. 404-15; reprinted as ch. 12 of his Economic Forces at Work, Indianapolis: Liberty Press (1977), pp. $301-23$. 
Jennings Jr. B. Frederic (2021), Everything You Know is Wrong'. A series of challenges and responses, The Journal of Philosophical Economics: Reflections on Economic and Social Issues, XIV (1-2), 208-217

Boland, Lawrence A. (1980), 'Friedman's methodology vs. conventional empiricism: a reply to Rotwein', Journal of Economic Literature, 18(4), 1555-57.

Boland, Lawrence A. (1986), Methodology for a New Microeconomics: The Critical Foundations, Boston: Allen \& Unwin.

Boulding, Kenneth E. (1966), 'The economics of knowledge and the knowledge of economics', American Economic Review, 56(2), 1-13, reprinted as chapter 1 of Lamberton, D. M. (ed.), Economics of Information and Knowledge, Middlesex, England: Penguin, 1971, pp. 21-36.

Feyerabend, Paul (1975), Against Method: Outline of an Anarchistic Theory of Knowledge, London: Verso.

Friedman, Milton (1953), 'The methodology of positive economics', ch. 1 of his Essays in Positive Economics, Chicago: University of Chicago Press, pp. 3-43.

Georgescu-Roegen, Nicholas (1970), 'The economics of production', American Economic Review, Papers and Proceedings, 60(2), 1-9.

Hicks, John R. ([1939] 1942), Value and Capital, $2^{\text {nd }}$ ed., Oxford, U.K.: Oxford University Press.

Hicks, John R. (1977), 'Preface (and Survey)', in his Economic Perspectives: Further Essays on Money and Growth, Oxford: Oxford University Press.

Jennings, Frederic B. Jr. (1985), Public Policy, Planning Horizons and Organizational Breakdown: A Post-Mortem on British Canals and Their Failure, Ph.D. dissertation, Department of Economics, Stanford University, Stanford, CA, available from University Microfilms International, 300 North Zeeb Road, Ann Arbor, MI 48106.

Jennings, Frederic B. Jr. (2008), 'A new economics of complementarity, increasing returns and planning horizons', in Wolfram Elsner and Hardy Hanappi (eds.), Varieties of Capitalism and New Institutional Deals, Cheltenham, England: Edward Elgar, pp. 281-97.

Jennings, Frederic B. Jr. (2009), 'Six choice metaphors and their social implications', The Journal of Philosophical Economics: Reflections on Economic and Social Issues, II(2), 34-77. 
Jennings Jr. B. Frederic (2021), Everything You Know is Wrong'. A series of challenges and responses, The Journal of Philosophical Economics: Reflections on Economic and Social Issues,

Jennings, Frederic B. Jr. (2012a), 'A theory of planning horizons (1): market design in a post-neoclassical world', Journal of Philosophical Economics, V(2), 537 ; also ch. 2 in Jennings (2017b).

Jennings, Frederic B. Jr. (2012b), 'A theory of planning horizons (2): the foundation for an ethical economics', Journal of Philosophical Economics, VI(1); also ch. 12 in Jennings (2017b).

Jennings, Frederic B. Jr. (2015), 'The case for increasing returns I: "The Hicksian Getaway" and "The Hirshleifer Rescue", The Journal of Philosophical Economics: Reflections on Economic and Social Issues, IX(1), 5-51.

Jennings, Frederic B. Jr. (2016a), 'The case for increasing returns II: the methods of planning horizons, increasing returns and complementarity', The Journal of Philosophical Economics: Reflections on Economic and Social Issues, IX(2), 2-39; also ch. 6 in Jennings (2017a).

Jennings, Frederic B. Jr. (2016b), 'Planning horizons as an ordinal entropic measure of organization', The Journal of Philosophical Economics: Reflections on Economic and Social Issues, X(1), 58-80.

Jennings, Frederic B. Jr. (2017a), The Economics of Horizon Effects (EHE), Saarbrucken, Germany: Lambert Academic Press.

Jennings, Frederic B. Jr. (2017b), The Human Ecology of Horizon Effects (HEHE), Saarbrucken, Germany: Lambert Academic Press.

Kahneman, Daniel, Slovic, Paul, and Tversky, Amos (1982), Judgment Under Uncertainty: Heuristics and Biases, Cambridge, U.K.: Cambridge University Press.

Kahneman, Daniel and Tversky, Amos (2000), Choices, Values and Frames, Cambridge, U.K.: Cambridge University Press.

Kaldor, Nicholas (1972), 'The irrelevance of equilibrium economics', Economic Journal, 82, 1237-55.

Kaldor, Nicholas (1973), 'Equilibrium theory and growth theory', in Michael Boskin (ed.), Economics and Human Welfare: Essays in Honor of Tibor Scitovsky, New York: Academic Press (1979), pp. 243-91. 
Jennings Jr. B. Frederic (2021), Everything You Know is Wrong'. A series of challenges and responses, The Journal of Philosophical Economics: Reflections on Economic and Social Issues,

Kaldor, Nicholas (1975), 'What is wrong with economic theory', Quarterly Journal of Economics, 89(3), 347-57.

Knight, Frank H. ([1924] 1969), 'Some fallacies in the interpretation of social cost', Quarterly Journal of Economics, 38; reprinted in Arrow, Kenneth J. and Scitovsky, Tibor (eds.), A.E.A. Readings in Welfare Economics, Homewood, IL: Irwin, pp. 213-27.

Myrdal, Gunnar (1978), 'Institutional economics', Journal of Economic Issues, 12(4), 771-83.

Pigou, Alfred C. (1927), 'The laws of diminishing and increasing cost', Economic Journal, 37(146), 188-97.

Pigou, Alfred C. (1928), 'An analysis of supply', Economic Journal, 38(150), 238-57. Polanyi, Michael (1958), Personal Knowledge: Towards a Post-Critical Philosophy, Chicago: University of Chicago Press.

Reder, Melvin W. (1982), 'Chicago economics: permanence and change', Journal of Economic Literature, 20(1), 1-38.

Reder, Melvin W. (1987), 'The Chicago School', in Eatwell, John; Milgate, Murray; and Newman, Peter (eds.), The New Palgrave Dictionary of Economics, Vol. 1, London: Macmillan, pp. 413-18.

Samuelson, Paul A. (1963), "Discussion" of Nagel', American Economic Review, Papers and Proceedings, 53(2), 231-36.

Simon, Herbert A. (1982-97), Models of Bounded Rationality, Vols. 1-3, Cambridge, MA: MIT Press.

Simon, Herbert A. (1983), Reason in Human Affairs, Stanford, CA: Stanford University Press.

Frederic B. Jennings Jr. is President of the Center for Ecological Economic and Ethical Education (CEEEE), Ipswich, Massachusetts (USA) and Advisory Board member of the Journal of Philosophical Economics (ecologicaleconomics@yahoo.com). 